\title{
The potential of organized physical activity/physical education for active lifestyle
}

\section{Michal Kudláček}

\begin{abstract}
We have to view the structure of sport preferences as a complex process reflecting the interactions between situational factors (socio-economic characteristics), motivational factors (reasons for taking part in sport activity) and needs, which are fulfilled through the realization of a particular activity.

The main objective of this survey was to analyze the structure of sport preferences and the level of physical activity (PA) of adolescents in relation with organized PA/ physical education (PE).

The character of our research was online - an internet-based research. We used two questionnaires: 1. online version of the sport preferences questionnaire, 2. online version of the International Physical Activity Questionnaire (IPAQ). Both of them are accessible in the INDARES.COM project (www.indares.com).

The survey proved its importance in the adequate choice of offered physical activity programs for children of the junior and senior school age with the potential to create conditions and environment for healthy and active lifestyle.

The realization of the online survey approved to be a useful research technique, and if we are able to improve the current system and make it more attractive it has the potential to be really a beneficial research tool.
\end{abstract}

Key words: High school, physical activity, adolescence, health, sport preferences, online survey. 


\section{Introduction}

The importance of the healthy lifestyle topic is possible to declare by the increasing number of surveys and research projects solving this topic. This topic is dealt with not only in the area of kinanthropology (kinesiology) but also in other areas of scientific efforts, e.g. public health, hygienic, pedagogical or epidemiological areas.

According to the kinesiology authors, lifestyle is one of the most important factors having a huge impact on people's health. In addition, there have been changes in the lifestyle of children and youth (Andresen et al., 1999; Biddle et al., 2009; Dunn et al., 1999; Laujunen et al., 2009; U.S. Department of Health and Human Services, 2000). This change is obvious also among leisure-time activities. An inadequate amount of physical activity has a negative impact on the health status and is one of the biggest risks in relation to mortality.

We have to view the structure of sport preferences as a complex process reflecting the interactions between situational factors (socio-economic characteristics), motivational factors (reasons for taking part on sport activity) and needs, which are fulfilled through the realization of a particular activity.

Previously conducted surveys in the field of sport preferences concludes visible dynamic in the development of the structure of sport preferences (Frömel, Novosad and Svozil, 1999; Kudláček, 2008; Kudláček and Frömel, 2012; Rychtecký, 2006).

There is insufficient evidence from the previous studies dealing with the structure of sport preferences referring to the interconnection between individual factors (socio-economic status, organized/structured physical activity, location, etc.), although these factors can considerably influence the total level of physical activity as well as the structure of sport preferences. There is no separate factor explaining the heterogeneity of the structure of sport preferences (and not only sport preferences) across the population. The acquired data give us an approximate prognosis of demanded activities on the national, regional and also local level. These data can also serve as an audit tool of the usage of existing available sources of physical activity, facilities and programs. This information can form the basis for the development of new facilities or for the innovation of the existing facilities.

\section{Objective}

The main objective of this survey was to analyze the structure of sport preferences and the level of physical activity (PA) of adolescents in relation with organized PA/physical education (PE). 
According to the main goal we addressed these partial objectives:

1. To check the possibility of using an online survey in the high school settings.

2. To contribute to details and easy monitoring of sport preferences.

\section{Methods}

The character of our research was online - internet-based research. We used two questionnaires: 1. online version of the sport preferences questionnaire, 2. online version of the International Physical Activity Questionnaire (IPAQ). Both of them are accessible in INDARES.COM project (www.indares.com) (Křen, Chemlík, Frömel, Fical and Kudláček, 2008).

The sport preferences questionnaire is designed for the purpose of finding information about the involvement of students/individuals in the sport activities within the organized/structured PA and unorganized/unstructured PA. Although there were some difficulties in the form of the creation of the sport preferences questionnaire (the questionnaire was already applied in the past but with a different content), we presume that this effort was fruitful. The sport preferences questionnaire is focused on 7 categories: 1 . Individual sports, 2. Team sports, 3. Conditional activities, 4. Water sport activities, 5. Outdoor sport activities, 6 . Martial arts, 7. Rhythmical and dancing activities; and one additional category 8 . Sport activities - overall.

The IPAQ questionnaire is a method ranking to the category using (functioning on the basis of self-evaluation/self-assessment - these methods are called "self-report population surveys"). The IPAQ questionnaire was developed and tested for 15-69 year old population. It is a worldwide spread way of collecting of the data from the field of physical activity, which enables to compare the acquired data either on the national level or on the international level. The IPAQ questionnaire assesses physical activity in the complex range of different areas. Besides the facts about the intensity of physical activity and its overall level within one week, we can acquire a complex of important and inspirational information about respondents or about the environment they are live in.

The project was carried out in the high school setting. Schools were randomly selected and invited to take part in the project. Only those students were accepted in the overall analysis whose filled in both the questionnaires so that it was possible to connect the information from the sport preferences area to the information related to the area of physical activity.

The research sample $(n=333)$ consisted of students of different high schools in the Czech Republic. The sample of girls is represented by 216 respondents (age $16.66 \pm 1.12$ years, height $167.58 \pm 6.31 \mathrm{~cm}$, weight $59.06 \pm 9.57 \mathrm{~kg}, \mathrm{BMI} 20.98 \pm 289$ ). The sample of boys is represented by 117 respondents (age 16.23 \pm 1.18 years, height $179.11 \pm 8.10 \mathrm{~cm}$, weight $69.57 \pm 11.05 \mathrm{~kg}, \mathrm{BMI} 2161 \pm 2.71)$. 
In accordance with many different factors (age, BMI, socio-economic status, location, presence/absence of organized PA) we tried to estimate possible trends in the physical activity development and also in the structure of sport preferences.

\section{Results}

Considering the factor of organized PA we noticed significant differences in vigorous PA and total PA in the sample of girls (girls with organized PA are more active than the girls without organized form of PA). Similar results were noticed in the group of boys but the differences within each category were much bigger than in girls. Moreover, we found out a significant difference in the category of moderate PA in comparison with the group of girls.

Considering the issue of organized PA and meeting the PA recommendations, we found out that both - girls and boys - participated in any kind of organized PA - are meeting PA recommendations most often.

Table 1: The level of physical activity considering the factor of organized physical activity (girls) - (MET-min/week)

\begin{tabular}{|l|c|c|c|c|c|c|c|c|}
\hline \multicolumn{8}{|c|}{ Physical activity in particular groups according to organized/unorganized PA } \\
\hline \multirow{2}{*}{ Factor of organized PA (n) } & \multicolumn{2}{|c|}{ Vigorous PA } & \multicolumn{2}{|c|}{ Moderate PA } & \multicolumn{2}{|c|}{ Walking } & \multicolumn{2}{|c|}{ Total PA } \\
\cline { 2 - 9 } & Mdn & $I Q R$ & $M d n$ & $I Q R$ & Mdn & IQR & Mdn & IQR \\
\hline $\begin{array}{l}\text { No organized PA } \\
(\mathrm{n}=87)\end{array}$ & 120 & 690 & 770 & 1,350 & 1,188 & 2,211 & 3,006 & 4,054 \\
\hline $\begin{array}{l}\text { With organized PA } \\
(\mathrm{n}=129)\end{array}$ & 720 & 2,100 & 1,265 & $2,097.5$ & $1,633.5$ & 2,384 & 4,168 & 5,350 \\
\hline
\end{tabular}

Note: Mdn - median, IQR - interquartile range

The presence of organized physical activity in girls (Table 1 ) reached significant differences in vigorous $P A\left(H=18.02 ; p=0.000 ; \eta^{2}=0.083\right)$, moderate $P A(H=5.07 ; p=0.024$; $\left.\eta^{2}=0.023\right)$ and also in total PA $\left(H=9.45 ; p=0.002 ; \eta^{2}=0.043\right)$. 
Figure 1: The level of physical activity considering the factor of organized physical activity (girls) - (MET-min/week)

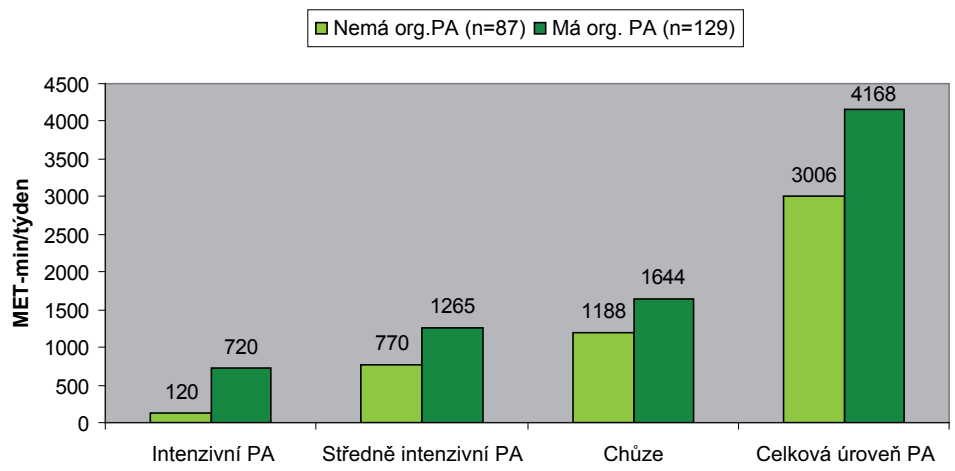

Table 2: Physical activity relating to factor of organized PA - ANOVA (girls)

\begin{tabular}{|c|c|c|c|c|c|}
\hline Physical activity & Organized PA & $n$ & $H$ & $p$ & $\eta^{2}$ \\
\hline \multirow{2}{*}{ Vigorous PA } & NO & 87 & \multirow{2}{*}{18.02} & \multirow{2}{*}{0.000} & \multirow{2}{*}{0.083} \\
\hline & YES & 129 & & & \\
\hline \multirow{2}{*}{ Moderate PA } & NO & 87 & \multirow{2}{*}{5.07} & \multirow{2}{*}{0.024} & \multirow{2}{*}{0.023} \\
\hline & YES & 129 & & & \\
\hline \multirow{2}{*}{ Walking } & NO & 87 & \multirow{2}{*}{2.02} & \multirow{2}{*}{0.154} & \multirow{2}{*}{0.009} \\
\hline & YES & 129 & & & \\
\hline \multirow{2}{*}{ Total PA } & NO & 87 & \multirow{2}{*}{9.45} & \multirow{2}{*}{0.002} & \multirow{2}{*}{0.043} \\
\hline & YES & 129 & & & \\
\hline
\end{tabular}

Note: $\mathrm{n}$ - sample size, $\mathrm{H}$ - Kruskal-Wallis ANOVA, $\mathrm{p}$ - level of significance, $\eta^{2}$ - coefficient "effect size" 
Table 3: The level of physical activity considering the factor of organized physical activity (girls) - (MET-min/week)

\begin{tabular}{|l|c|c|c|c|c|c|c|c|}
\hline \multicolumn{8}{|c|}{ Physical activity in particular groups according to organized/unorganized PA } \\
\hline \multirow{2}{*}{ Factor of organized PA $(\mathrm{n})$} & \multicolumn{2}{|c|}{ Vigorous PA } & \multicolumn{2}{|c|}{ Moderate PA } & \multicolumn{2}{|c|}{ Walking } & \multicolumn{2}{|c|}{ Total PA } \\
\cline { 2 - 10 } & Mdn & $I Q R$ & Mdn & IQR & Mdn & IQR & Mdn & IQR \\
\hline $\begin{array}{l}\text { No organized PA } \\
(\mathrm{n}=35)\end{array}$ & 210 & 840 & 1,162 & 1,320 & 1,039 & 2,277 & 3,222 & 3,681 \\
\hline $\begin{array}{l}\text { With organized PA } \\
(\mathrm{n}=82)\end{array}$ & 1,590 & 2,700 & 1,732 & 3,235 & 1,411 & 2,392 & 6,350 & 7,219 \\
\hline
\end{tabular}

Note: Mdn - median, IQR - interquartile range

The factor of organized PA had a bigger influence on the structure of PA in boys than in girls (Table 3 ) although the differences were recognized in the same types of PA (the differences were much bigger). The presence of organized PA reached significant values in vigorous PA, moderate PA and also in total PA (Table 4).

Table 4: Physical activity relating to factor of organized PA - ANOVA (boys)

\begin{tabular}{|c|c|c|c|c|c|}
\hline Physical activity & Organized PA & $n$ & $H$ & $p$ & $\eta^{2}$ \\
\hline \multirow{2}{*}{ Vigorous PA } & NO & 35 & \multirow{2}{*}{19.80} & \multirow{2}{*}{0.000} & \multirow{2}{*}{0.17} \\
\hline & YES & 82 & & & \\
\hline \multirow{2}{*}{ Moderate PA } & NO & 35 & \multirow{2}{*}{4.61} & \multirow{2}{*}{0.031} & \multirow{2}{*}{0.039} \\
\hline & YES & 82 & & & \\
\hline \multirow{2}{*}{ Walking } & NO & 35 & \multirow{2}{*}{2.09} & \multirow{2}{*}{0.148} & \multirow{2}{*}{0.018} \\
\hline & YES & 82 & & & \\
\hline \multirow{2}{*}{ Total PA } & NO & 35 & \multirow{2}{*}{11.63} & \multirow{2}{*}{0.000} & \multirow{2}{*}{0.100} \\
\hline & YES & 82 & & & \\
\hline
\end{tabular}

Note: $\mathrm{n}$ - sample size, $\mathrm{H}$ - Kruskal-Wallis ANOVA, $\mathrm{p}$ - level of significance, $\eta^{2}$ - coefficient "effect size" 
Figure 2: The level of physical activity considering the factor of organized physical activity (boys) - (MET-min/week)

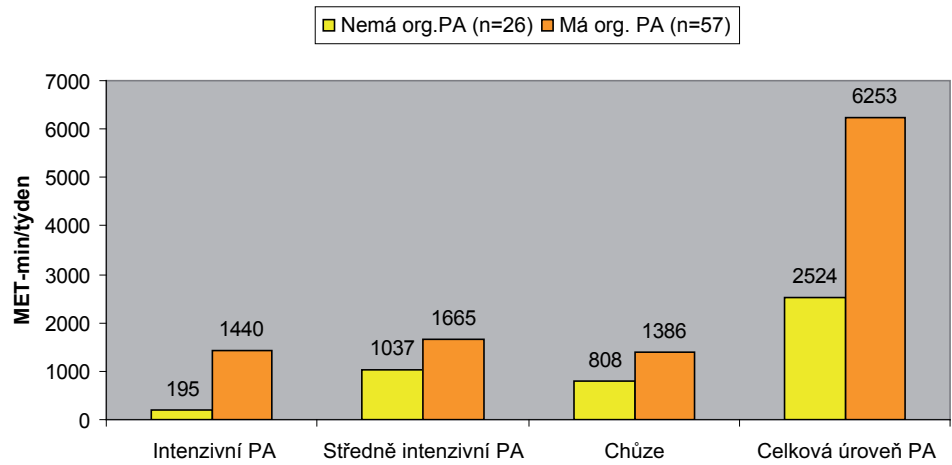

The structure of sport preferences in girl and boys was assessed in consideration with the gender factor. The main purpose of this part was to find out gender differences and other inequalities in the sport preferences structure.

Table 5: Sport preferences structure - Individual sports (inter-gender comparison)

\begin{tabular}{|c|c|c|}
\hline \multicolumn{3}{|c|}{ Individual sports } \\
\hline & Boys & Girls \\
\hline Athletics & 9 & 9 \\
\hline Badminton & 10 & 7 \\
\hline Bowling (nine pins, snooker, pool, petanque) & 8 & 6 \\
\hline Ice-skating (figure skating, speedskating) & 13 & 5 \\
\hline Cycling & 1 & 2 \\
\hline Golf (minigolf) & 11 & 14 \\
\hline Canoying, rowing & 14 & 15 \\
\hline Combined sports (triathlon, modern pentathlon) & 16 & 17 \\
\hline Cross-country skiing (biathlon, nordic combination) & 15 & 16 \\
\hline Swimming & 2 & 1 \\
\hline Sport gymnastics & 17 & 13 \\
\hline Squash (ricochet, racquetball) & 12 & 11 \\
\hline Shooting, archery & 6 & 12 \\
\hline Table tennis & 3 & 10 \\
\hline Tennis (soft tennis) & 5 & 4 \\
\hline Downhill skiing (alpine, acrobatic, speed) & 4 & 3 \\
\hline Snowboarding & 7 & 8 \\
\hline
\end{tabular}

Note: dominant activities and anticipated trends/development are in bold 
The category of "Individual sports" was chosen as an example of the acquired results mainly because of the voluminousness of the results (Table 5). More significant differences were found out in various sport activities. The more prefered activites among girls are badminton, ice-skating and sport gymnastics. On the other hand - in boys the more prefered ones are golf, shooting, archery and table tennis. The differences between other sport activities were not significant. The overall correlation coefficient for the category of Individual sports was high $(r=0.76)$.

The respondents were also asked to mark the most prefered activity, and this part of our survey gave the following results. The most prefered sport activity in girls is modern dances (13\%), followed by cycling ( $8 \%)$, cyclotourism (7\%), Latino-American dances $(6 \%)$ and sport aerobics (6\%). Other activites are in the minority.

The most prefered activity in boys is soccer (33\%), followed by floorball (11\%), tennis ( $8 \%)$, motosports (6\%) and swimming (6\%). Other sports are in the minority but the number of mentioned sports is not so big as in girls.

\section{Discussion}

The acquired results indicate that differences in sport activities between boys and girls are not so obvious. Despite a certain dynamic in the development of the sport preferences structure (compared to previous studies) we identified a certain group of sports, which is prefered on regular basis (e. g. football, floorball, basketball, running (jogging)). The most prefered activities in girls are - swimming, downhill skiing, cycling, volleyball, handball, floorball, basketball, power exercise, water exercise, kick-box (thai-box), LatinAmerican dances and modern dances. The most preferred activities in boys are - swimming, downhill skiing, cycling, football, florball, basketball, running (jogging), power exercise, diving, karate, kick-box (thai-box) and martial dances.

Regarding the PA survey, the following results were acquired. The total range of the amount of PA (average values) is in the interval from 2,372 MET-minutes/week in 15-years-old girls to 4,467 MET-minutes/week in 17-years-old girls. In the sample of boys we found out the average values from 4,270 MET-minutes/week in 16-years-old boys to 6,564 MET-minutes/week in $\geq 18$-years-old boys. The amount of PA has an increasing tendency in both girls and boys, which is not identified by the previous surveys proclaiming a decreasing tendency of the amount of PA (Gordon-Larse, McMurray and Popkin, 1999; Harrel et al., 2005; Sallis, 2000; van Mechelen, Twisk, Post, Snel and Kemper, 2000). On the other side Aaron et al. pointed out that there was positive trend in boys (Aaron et al., 1993), compared to a negative trend in girls.

The main factor we worked with was the factor of organized PA. The organized form of PA is much more effective than the unorganized form of PA from the perspective of effectiveness. Moreover, organized PA of children and youth is positively correlated 
with the frequency of leisure-time PA in adulthood (Kjønniksen, Anderssen and Wold, 2009). Considering the influence of the factor of organized PA we found no significant differences either in girls or in boys. The differences were noticed mainly in the category of vigorous PA and total PA, whereas the differences were much higher in boys than in girls.

The relation of organized PA to school PE is more than obvious, and we can use our results as an implication for the school settings. It can also serve as a tool of innovation of the currently offered sports programs and curricula.

Schools are important in shaping of values and beliefs in young people. If done well, physical education is one medium that can positively impact values associated with participation in recreation and sport.

Physical education programs in secondary schools have evolved over the years, moving from a more sports-oriented curriculum to a balanced approach that stresses the teaching of healthy lifestyle choices. PE design diversified programs that get students moving even if they are not inclined towards athletics.

Sports are a part of the physical education curriculum at most high schools, but fitness activities usually take a larger role. PE teachers are actively involved in designing the curriculum that provides health and fitness opportunities for their students. They want students to leave high schools with knowledge of areas that include cardiovascular fitness, body composition, endurance, strength, flexibility and stress management.

High school teachers are acutely aware of the challenges in trying to engage and sustain the interest of adolescents. In today's society, sport and physical activity touch most students, often playing a central role in their lives. This high level of involvement offers physical educators windows of opportunity to help students appreciate and critique the role of physical activity and sport in their own lives and in society. The curricular approach presented in this article describes one attempt to make a meaningful connection between what occurs in the name of physical education and the place of sport in students' live.

The quality and meaningfulness of school physical education have been questioned among practitioners. Even thought we know much about the purpose and benefits of school physical education programs, we know little about how to challenge students in physical education classes. Throughout the past decade, as a new century has approached, the quality of school physical education has been an ongoing focus in the physical education literature. In particular, the meaningfulness and contribution of physical education as a subject in today's schools have been questioned by teachers, students, administrators, and parents. Recent literature (Kirk, 1994; Lawson, 1995, 1998; Macdonald and Brooker, 1997; Siedentop, 1992; Stroot, 1994; Tinning and Fitzclarence, 1992) has analyzed the crisis of school physical education in term of loss of student interest, lack of identity of physical education as a subject, and lack of accountability for student learning. 
What is one to make of the fact that physical education in the schools is meaningless, boring, and irrelevant while physical activities outside the school setting remain significant (Spencer, Edwards and Spencer, 1991; Tinning and Fitzclarence, 1992). School physical education has obviously failed by disregarding the nature of student culture, students' motivation to participate in physical activities, and their gender, socioeconomic, and ethnic backgrounds.

All school programs should provide the students with challenging educational opportunities.

\section{Conclusions}

1. The survey proved its importance in adequate choice of offered physical activity programs in junior and senior school age with the potential to create conditions and environment for healthy and active lifestyle.

2. The presence of organized physical activity in girls reached significant differences in vigorous PA, moderate PA and also in total PA. There were differences in the same categories also in boys but the differences were much bigger.

3. Boys are more active than girls.

4. The sport preferences survey shows that the most prefered sport activities in girls are modern dances (13\%), cycling (8\%), cyclotourism (8\%), Latino-American dances (6\%) and sport aerobics (6\%).

5. The sport preferences survey shows that the most prefered sport activities in boys are soccer (33\%) followed by floorball (11\%), tennis (8\%), motosports (6\%) and swimming (6\%).

6. Despite particular dynamics in the development of the structure of sport preferences (compared to previous surveys) we can conclude that there is a group of sports, which stays on the top of the prefered ranking and they are relatively more stable (soccer, volleyball, aerobics, swimming).

7. Consideration of each particular factor (organized PA, age, gender, socio-economic status) is specific for each research sample.

8. The usage of this survey tool (INDARES) can help us anticipace the possible development or stability of prefered sport activities. This can serve us as a tool for optimization of the proposed physical activity programs/curriculum.

The realization of the online survey has approved to be a useful research technique, and if we are able to improve the current system and make it more attractive it has the potential to be a really beneficial research tool. 


\section{References}

Aaron, D. J., Kriska, A. M., Dearwater, S. R., Anderson, R. L., Olsen, T. L., Cauley, J. A. \& Laporte, R. E. (1993). The Epidemiology of Leisure Physical Activity in an Adolescent Population. Medicine \& Science in Sports \& Exercise: Applied Sciences. No. 25 (7), pp. 765-883.

Andersen, R. E. Wadden, T. A., Barlett, S. J., Zemel, B., Verde, T. J. \& Franckowiak, S. C. (1999). Effects of Lifestyle Activity Vs Structured Aerobic Exercise in Obese Women: A Randomized Trial. The Journal of American Medical Association. No. 281 (4), pp. 335-340.

Biddle, S. J. H., Soos, I., Hamar, P., Sandor, I., Simonek, J. \& Karsai, I. (2009). Physical Activity and Sedentary Behaviours in Youth: Data from Free Central-Eastern European Countries. European Journal of Sport Science. No. 9 (5), pp. 295-301.

Dunn, A. L., Marcus, B. H., Kampert, J. B., Garcia, M. E., Kohl, H. W. \& Blair, S. N. (1999). Comparison of Lifestyle and Structured Interventions to Increase Physical Activity and Cardiorespiratory fitness. The Journal of the American Medical Association. 1999, No. 281 (4), pp. 327-334.

Frömel, M., Novosad, J., \& Svozil, Z. (1999). Pohybová aktivita a sportovní zájmy mládeže. Olomouc: Univerzita Palackého.

Gordon-Larsen, P., Mcmurray, R. G. \& Popkin, B. M. (1999). Adolescent Physical Activity and Inactivity Vary by Etnicity: The National Longitudinal Study of Adolescent Health. The Journal of Pediatrics. No. 135, pp. 301-306.

Harrell, J. S., Mcmurray, R. G., Baggett, C. D., Pennell, M. L. Pearce, P. F. \& Bangdiwala, S. I. (2005). Energy Cost of Physical Activities in Children and Adolescents. Medicine \& Science in Sports \& Exercise: Applied Sciences, no. 37 (2), pp. 329-336.

Kirk, D. (1994). "Making the Present Strange": Sources of the Present Crisis in Physical Education. Discourse, no. 15 (1), pp. 46-53.

Kjønniksen, L., Anderssen, N. \& Wold, B. (2009). Organized Youth Sport as a Predictor of Physical Activity in Adulthood. Scandinavian Journal of Medicine \& Science in Sports, no. 19 (5), pp. 646-654.

Křen, F., Chmelík, F., Frömel, K., Fical, P. \& Kudláček, M. (2012). Dotazníky PPA a IPAQ pro Indares.com [Computer software]. Olomouc: Univerzita Palackého.

Kudláček, M. (2008). Sport Preferences Survey - Future of Martial Arts. Archive sof Budo, no. 4, pp. 101-105. ISSN

Kudláček, M. \& Frömel, K. (2012). Sportovní preference a pohybová aktivita studentek a studentů středních škol. Olomouc: Univerzita Palackého.

Lajunen, H-R., Keski-Rahkonen, A., Pulkkinen, L., Rose, R. J., Rissanen, A. \& Kaprio, J. (2009). Leisure Activity Patterns and Their Associations with Overweight: A Prospective Study among Adolescents. Journal of Adolescence, no. 32, pp. 1089-1103.

Lawson, H. (1995). School Reform, Families, and Health in the Emergent National Agenda for Economic and Social Improvement: Implications. Quest, no. 45, pp. 289-307.

Lawson, H. (1998). Rejuvenating, Reconstituting, and Transforming Physical Education to Meet the Needs of Vulnerable Children, Youth, and Families. Journal of Teaching in Physical Education. No. 18, pp. 2-25.

Macdonald, D. \& Brooker, R. (1997). Moving Beyond the Crises in Secondary Physical Education: An Australian Initiative. Journal of Teaching in Physical Education. no. 16, pp. 155-175.

Rychtecký, A. (2006). Monitorování účasti mládeže ve sportu a pohybové aktivitě v České republice. Praha: Univerzita Karlova.

Sallis, J. F. (2000). Age-related Decline in Physical Activity: A Synthesis of Human and Animal Studies. Medicine \& Science in Sports \& Exercise: Applied Sciences, no. 32 (9), pp. 1598-1600.

Siedentop, D. (1992). Thinking Differently about Secondary Physical Education. Journal of Physical Education, Recreation, and Dance, no. 63 (7), pp. 67-73. 
Spencer, S., Edwards, W. \& Spencer, D. (1991). Practical Suggestions for Implementing Nontraditional/Adventure Education into the High School Curriculum. Physical Educator, no. 48 (4), pp. 206-210.

Stroot, S. A. (1994). Contemporary Crisis or Emerging Reform? A Review of Secondary School Physical Education. Journal of Teaching in Physical Education, 13, no. 4, pp. 333-341.

Tinning, R. \& Fitzclarence, L. (1992). Postmodern Youth Culture and the Crisis in Australian Secondary School Physical Education. Quest, 44, no. 3, pp. 287-303.

U. S. Department of Health and Human Services. Healthy People 2010: Leading Health Indicators. 2000. Retrieved from http://www.healthypeople.gov/LHI/

Van Mechelen, W., Twisk, J. W. R., Post, G. B., Snel, J. \& Kemper, C. G. (2000). Physical Activity of Young People: The Amsterdam Longitudinal Growth and Health Study. Medicine \& Science in Sports \& Exercise: Applied Sciences. Vol. 32, no. 9, pp. 1610-1616.

\section{Acknowledgements}

This article was supported by the research grant "Physical Activity and Inactivity of Inhabitants of the Czech Republic in the Context of Behavioural Changes" with identification number MSM 6198959221.

\section{Contact:}

Mgr. Michal Kudláček, Ph.D.

Department of Recreology

Faculty of Physical Culture

Palacký University, Olomouc

tř. Míru 115

77111 Olomouc

Czech Republic

E-mail:michal.kudlacek@upol.cz 